\title{
Good Health Status of Older and Oldest Elderly in Jamaica: Are there Differences between Rural and Urban Areas?
}

\author{
Paul A. Bourne* \\ Department of Community Health and Psychiatry, Faculty of Medical Sciences, The University of the West Indies, \\ Mona, Jamaica, West Indies
}

\begin{abstract}
The aim of the current study was to examine the good health status of older and oldest elderly Jamaicans as well as to determine predictors of this health status. A sub-sample of 1,069 respondents (42.4 percent men and 57.6 percent women) who indicated being 75 years and older were used for this study. This is extracted from a larger nationally cross-sectional survey of 25,018 respondents in 2002. The stratified multistage probability sampling technique was used to draw the survey respondents, which reflects the socio-demographic characteristic of the Jamaican population, and makes the sample generalizable on the population. A self-administered questionnaire was used to collect the data from the sample; and the interviewers were trained to collect data. The data were entered, stored and retrieved in SPSS 16.0. Descriptive statistics were used to examine the demographic characteristics of the sample; chi-square was used to investigate non-metric variables, and logistic regression was the multivariate technique chosen to determine predictors of good health status. Two factors were found to be statistically significant predictors of good health status of older and oldest elderly respondents. These were area of residence and sex of respondents. Older and oldest elderly men reported a greater good health status than old and oldest elderly women ( $\mathrm{OR}=1.410 ; 95 \% \mathrm{CI}: 1.048-1.897)$. On the other hand, there was no statistical difference between the self-reported diagnosed (chronic) recurring illness and age cohort of the sample. Rural older and oldest elderly respondents indicated the lowest good health status $(\mathrm{OR}=1.00)$ compared to other residents (urban: $\mathrm{OR}=1.670 ; 95 \%$ CI: $1.071-2.606$; and other town dwellers: $\mathrm{OR}=1.847 ; 95 \% \mathrm{CI}: 1.327-2.572$ ). Good health of this age cohort is not influenced by income or social standing, and there is a need to examine lifestyle risk factors; disease indicators and psychological conditions, as this may provide more answers to the good health of Jamaicans 75 years and older. A quantitative assessment has provided us with answers, but it is clear from the findings that more information is needed on this age cohort. The researcher recommends the use of qualitative methodologies to provide in-depth understanding of those factors that determine good health of this age cohort.
\end{abstract}

Keywords: Good health, determinants of good health, older elderly, oldest elderly, Jamaica.

\section{INTRODUCTION}

Globally, statistics revealed that the growth rate for people 80 years and older was 3.9 percent $(2000-2005)$ and that this was twice more than that for elderly 60 years and over. Comparatively, the average annual rate of growth for the population 80 years and older was 4.0 percent for Latin America and the Caribbean, which was 1.4 times more than that for the population $60+$ years [1]. For the Caribbean, the average annual growth rate for the population $80+$ years was 0.7 times less than the younger elderly. Moreover, the annual rate of growth for the population of Jamaica since 2003 is between 0.50 and 0.45 , which is less than the rate of growth for the population $60+$ years $(1.2$ percent) and $80+$ years (2.0 percent). People are not only living longer in the Caribbean, but traditional health indicators such as total fertility rate, crude birth and death rates, infant and maternal mortality have been relatively stable since 1996 .

For some time now, Caribbean nations such as Barbados, Cuba, Dominica, Guadeloupe, Jamaica, Martinique and

*Address correspondence to this author at the Department of Community Health and Psychiatry, Faculty of Medical Sciences, The University of the West Indies, Mona, Jamaica, West Indies; Tel: (876) 457-6990;

E-mail: paulbourne1@yahoo.com
Trinidad and Tobago have been experiencing demographic transition [1-5]. This is a shifting of the population from younger ages to older ones (ages 60 years and older or elderly) owing to reduced child and adult mortality, better public health and environmental conditions, higher standard of living and a reduction in the population under 15 years. Those countries have in excess of 8 percent (2007) of their population 60 years and older [1-5]. Some demographers argue that population ageing occurs when 8 percent and more of a country's population are elderly [6]. Population ageing in the Caribbean is similar to the experiences of the rest of the world, but it is more rapid, with a high degree of poverty and significant gender differences and inequalities. Another noticeable aspect of the ageing process is the average annual rate of growth of the population 80 years and older in comparison with $60+$ years.

Undoubtedly ageing is a biological process, and continues throughout one's lifetime. Over the lifespan of an individual he/she shifts from one birthday to the next, and equally so is the case for morbidity, health status and quality of life. Health literature has shown that biological ageing is correlated with increased morbidity, mortality and poor health status $[7,8]$, which explains the health disparity (including functional and working capacity) between younger and older ages (60+ years). This justifies the rationale for the 
WHO's disability adjusted life expectancy (DALE or healthy life expectancy) [9]. Life expectancy that has been widely used by demographers to assess the health status of a population is computed from mortality data, and a critical assumption is that all people subscribe to the same mortality patterns. Embedded in this construct is the fact that living means good health status. This, however, is not the case, as people can be alive but not enjoying their lived years, because of ailments which are not life-threatening but debilitating health conditions. This gave rise to the WHO's recognition that the emphasis should not be on life expectancy but on healthy life expectancy. Here, it argued for the discounting of life expectancy for the number of years lived with disabilities or illnesses.

The elderly have a greater probability of facing health conditions compared to people of young ages owing to their biological composition, which implies that the older an elderly person becomes, the less likely it is that he/she will have good health. The WHO [1] calculated that developing countries' life expectancy should be discounted by 9 years, and this should be 8.4 years for men and 9.5 years for women in Jamaica. Although life expectancy has doubled for men and women in Jamaica over the last 100 years $[2,10]$, people are living longer with more disabilities and health conditions. According to WHO [11], "In developing countries, their (elderly - ages 60 years and older) situation is generally much less widely-known and their needs and contributions have been largely invisible." This is not the case in Jamaica, as Bourne $[3,10,12]$, Eldemire [13-20], and others have [2127] extensively reviewed different aspects of the life of people and/or elderly women and men. Although those studies have been done, an extensive review of health literature in Jamaica found no study that has investigated determinants of good health status of the older and oldest elderly Jamaicans. Hence, the aim of this study is to examine factors that explain good health status of the older elderly (ages 75 to 84 years) and the oldest elderly (ages $85+$ years) in Jamaica.

\section{METHODS}

The sub-sample for the current study was 1,069 older and oldest elderly respondents (ages of 75 years and older) extracted from a nationally representative cross-sectional survey of 25,018 Jamaicans (Jamaica Survey of Living Status, JSLC). The survey was drawn using stratified random sampling. This design was a two-stage stratified random sampling design where there was a Primary Sampling Unit (PSU) and a selection of dwellings from the primary units. The PSU is an Enumeration District (ED), which constitutes of a minimum of 100 dwellings in rural areas and 150 in urban areas. An ED is an independent geographic unit that shares a common boundary. This means that the country was grouped into strata of equal size based on dwellings (EDs). Based on the PSUs, a listing of all the dwellings was made, and this became the sampling frame from which a Master Sample of dwelling was compiled, which in turn provided the sampling frame for the labour force. Ten percent was selected for the survey (JSLC).

This study used JSLC 2002 which was conducted by the Statistical Institute of Jamaica (STATIN) and the Planning Institute of Jamaica (PIOJ) between June and October 2002. The researchers chose this survey based on the fact that it was the second largest sample size for the survey in its history (since 1988 to 1998), and in that year the survey contained questions on crime and victimization and the physical environment, unlike previous years. A self-administered questionnaire was used to collect the data, which were stored and analyzed using SPSS for Windows 16.0. The questionnaire was modelled from the World Bank's Living Standards Measurement Study (LSMS) household survey. There are some modifications to the LSMS, as JSLC is more focused on policy impacts. The questionnaire covered areas such as socio-demographic, economic and wealth variables, crime and victimization, social welfare, health status, health services, nutrition, housing, immunization of infants and physical environment. The non-response rate for the survey was $27.7 \%$.

Descriptive statistics such as mean, standard deviation (SD), frequency and percentage were used to analyze the socio-demographic characteristics of the sample. Chi-square was used to examine the association between non-metric variables, and an Analysis of Variance (ANOVA) was used to test the relationships between metric and nondichotomous categorical variables. Logistic regression examined the relationship between the dependent variable and some predisposed independent (explanatory) variables, because the dependent variable was a binary one (self-reported health status: 1 if reported good health status and 0 if poor health).

The results were presented using unstandardized Bcoefficients, Wald statistics, Odds ratio and confidence interval $(95 \% \mathrm{CI})$. The predictive power of the model was tested using the Omnibus Test of Model, and Hosmer and Lemeshow [28] was used to examine goodness of fit of the model. The correlation matrix was examined in order to ascertain whether autocorrelation (or multicollinearity) existed between variables. Based on Cohen and Holliday [29] correlation can be low (weak) - from 0 to 0.39 ; moderate - 0.40.69 , and strong $-0.7-1.0$. This was used to exclude (or allow) a variable in the model. Wald statistics were used to determine the magnitude (or contribution) of each statistically significant variable in comparison with the others, and the Odds Ratio (OR) for the interpreting of each significant variable.

Multivariate regression framework $[10,12]$ was utilized to assess the relative importance of various demographic, socio-economic characteristics, physical environment and psychological characteristics, in determining the health status of Jamaicans; and this has also been employed outside of Jamaica [30, 31]. This approach allowed for the analysis of a number of variables simultaneously. Secondly, the dependent variable is a binary dichotomous one and this statistic technique has been utilized in the past to do similar studies. Having identified the determinants of health status from previous studies, using logistic regression techniques, final models were built for women in general as well as for each of the geographical sub-regions (rural, peri-urban and urban areas) using only those predictors that independently predict the outcome. A p-value of 0.05 was used to for all tests of significance.

The proposed model which this study seeks to evaluate is the health status of Bourne $[10,12]$ which was used previously to model health status of Jamaican. 
$\mathrm{H}_{\mathrm{i}}=f\left(\mathrm{~W}_{\mathrm{i}}, \mathrm{HH}_{\mathrm{i}}, \mathrm{Pmc}_{\mathrm{i}}, \mathrm{C}_{\mathrm{i}}, \mathrm{MR}_{\mathrm{i}}, \mathrm{AR}_{\mathrm{i}}, \mathrm{ED}_{\mathrm{i}}, \mathrm{SS}_{\mathrm{i}}, \mathrm{CR}_{\mathrm{i}},\left(\sum \mathrm{NA}_{\mathrm{i}}\right.\right.$, $\left.\left.\mathrm{PA}_{\mathrm{i}}\right), \mathrm{M}_{\mathrm{i}}, \mathrm{F}_{\mathrm{i}}, \mathrm{CH}_{\mathrm{i}}, \mathrm{A}_{\mathrm{t}}, \mathrm{X}_{\mathrm{i}}, \mathrm{A}_{\mathrm{i}}, \mathrm{HI}_{\mathrm{i}}, \mathrm{LL}_{\mathrm{i}}, \mathrm{En}_{\mathrm{i}}, \mathrm{Y}_{\mathrm{i}}, \mathrm{V}_{\mathrm{i}}, \varepsilon_{\mathrm{i}}\right)(1)$

Health status of person $\mathrm{i} \mathrm{H}_{\mathrm{i}}$, is a function of $\mathrm{W}_{\mathrm{i}}$ is the two wealthiest quintiles of person i. 1 if yes, 0 if two poorest quintiles; $\mathrm{HH}_{\mathrm{i}}$ is household head of person i. 1 if yes, 0 if otherwise; $\mathrm{Pmc}_{\mathrm{i}}$ is cost of medical care of person $\mathrm{i}$, in US dollars; $\mathrm{C}_{\mathrm{i}}$ is average consumption per person in household, in Jamaican dollars; $\mathrm{MR}_{\mathrm{i}}$ is marital status of person $\mathrm{i}$; $\mathrm{AR}_{\mathrm{i}}$ is area of residence of person $i ; \mathrm{ED}_{\mathrm{i}}$ is educational level of person i; $\mathrm{SS}_{\mathrm{i}}$ is having social support of person i. 1 if, yes; and 0 if no; $\mathrm{CR}_{\mathrm{i}}$ is crowding of person $\mathrm{i}$, in numbers; $\left(\sum \mathrm{NA}_{\mathrm{i}}\right.$, $\mathrm{PA}_{\mathrm{i}}$ ) is a psychological status which is the summation of negative affective status of person $\mathrm{i}, \mathrm{NA}_{\mathrm{i}}$ where values are in continuous numbers; and, $\mathrm{PA}_{\mathrm{i}}$ is positive affective psychological status of person $\mathrm{i}$, where values are in continuous numbers; $\mathrm{M}_{\mathrm{i}}$ is number of men in household of person $\mathrm{i} ; \mathrm{F}_{\mathrm{i}}$ is number of women in household of person $\mathrm{i} ; \mathrm{CH}_{\mathrm{i}}$ is number of children below the age of 14 years of person i; $A_{t}$ is asset owned of person $i$, in continuous numbers; $X_{i}$ is gender of respondent $\mathrm{i}$; $\mathrm{Ai}$ is age of person $\mathrm{i}$, in continuous numbers; $\mathrm{HI}_{\mathrm{i}}$ is ownership of private health insurance ; $\mathrm{LL}_{\mathrm{i}}$ is living arrangement where $1=$ living with family members or relative, and $0=$ otherwise; $\mathrm{En}_{\mathrm{i}}$ is physical environment of person i. 1 if affected by flood, landslides, soil erosion, 0 if no; $\mathrm{Y}_{\mathrm{i}}$ is average income per person in household (this variable is measured by total expenditure, and $\mathrm{V}_{\mathrm{i}}$ is crime of person $\mathrm{i}$, where values are continuous numbers, and $\varepsilon_{\mathrm{i}}$ is the residual error.

Using data on older and oldest elderly Jamaicans, this study found that self-reported health status can be predicted by two variables [Eqn. (2)]

$\mathrm{H}_{\mathrm{i}}=f\left(\mathrm{AR}_{\mathrm{i}}, \mathrm{X}_{\mathrm{i}}, \varepsilon_{\mathrm{i}}\right)$

\section{MEASURES}

Self-reported Health Status is self-assessed illness (cold, diarrhoea, asthma attack, hypertension, diabetes mellitus or any other illnesses) reported by respondents in the last 4 weeks of the survey period. Good Health Status is a dummy variable, where $1=$ good health (not reporting an ailment, injury or dysfunction) and $0=$ poor health (self-reported illness, injury or ailment). Household crowding is the average number of persons living in a room excluding kitchen, bathroom and verandah. Physical Environment is the summation of responses as reported by respondents on suffering the effects of landsides, property damage due to rains, flooding; or soil erosion in the last 4 weeks of the survey period. Psychological Conditions are the psychological state of an individual, and this is sub-divided into positive and negative affective psychological status. Positive Affective Psychological Status refers to the number of responses that are hopeful and optimistic about the future and life generally. Negative Affective Psychological Status refers to the number of respondents having lost a breadwinner and/or family member, experienced loss of property, been made redundant, or failed to meet household and other obligations. Age is the number of years lived, which is also referred to as age at last birthday. This is a continuous variable, ranging from 15 to 100 years. Age is classified into three groups: young respondents aged 15 to 30 years, older adults 31 to 59 years, and elderly 60 years and older. Crime and Victimization Index (Crime Index) measures the number of cases and severity of crimes committed against a person or his/her family members, but not against property. Using Cohen and Holliday's [29] correlation guideline, low crime was from 0 to 34; moderate from 35 to 61 , and high from 62 to 88 . Older elderly is defined as the chronological age of 75 years to 84 years. Oldest elderly is the chronological age of 85 years and older. Social support (or network) denotes different social networks in which the individual is involved ( $1=$ membership of and/or visits to civic organizations or having friends that visit one's home or with whom one is able to network, $0=$ otherwise).

\section{RESULTS}

\section{Demographic Characteristic of Sample}

The sample was 1,069 respondents $(42.5$ percent men and 57.6 percent women), of which there were 74.2 percent older elderly and 25.8 percent oldest elderly. Forty-three percent were classified as either poor or poorest; 71 percent were never married (included common-law), separated, divorced or widowed; 5 percent had private health insurance coverage; 8 percent received some form of retirement; 68 percent lived in rural areas compared to 32 dwelling in urban areas (of this 21 percent lived in other towns and 11 in cities); 67 percent had at most primary level education, of which 2 percent reported tertiary level education; 48.3 percent indicated that they had good health compared to 51.7 percent with poor health status; 41 percent reported having suffered the effects of soil erosion, landslide or some other form of natural disaster. Crimes affecting the sample were very low $(1.12 \pm 0.84) ; 52.1$ percent reported visits to private health care facilities compared to 47.9 percent public health care facilities, mean consumption per person in household was US\$699.13 \pm US\$627.64; 55.7 percent of respondents indicated that they had social support; 20.7 percent lived alone; 35.5 percent were living with grandchildren, and 29.2 percent of the sample was married.

On further examination of some of the aforementioned variables by age cohort, interesting results came to light (Table 1). The findings revealed that there was no statistical difference between the reported good health status of older elderly respondents $(48.7 \%)$ compared to that of the oldest elderly respondents $(45.5 \%), p=0.385$. The same thing was found with private health insurance coverage for older elderly respondents compared to oldest elderly respondents $(\mathrm{p}=$ $0.184)$. However, a statistical correlation was found between sex of respondents and age cohort $(p=0.003)$. Fifty-five and one tenth percent of older elderly respondents were females compared to 44.9 percent of the oldest elderly. More of the respondents dwelled in rural areas, with there being no statistical difference between older elderly and oldest elderly respondents $(\mathrm{p}=0.121)$. A high percentage of the sample owned their own home (87.2 percent), and there was no statistical difference between the older elderly ( 87.7 percent) and oldest elderly (85.5 percent) (Table $\mathbf{1}$ ).

The crime index showed that this affected more urban than rural elderly respondents (urban $1.61 \pm 7.53$; rural 0.74 $\pm 3.02)(\mathrm{p}=0.007)($ Table 2$)$. The findings revealed that poverty was 2.2 times greater in rural than in urban areas (12.4 percent of urban residents were below the poverty line); higher level education was greater in urban than rural areas; private health insurance coverage was 5.2 times greater for urban residents compared to rural residents $(2.0$ 
Table 1. Sociodemographic Characteristics of Sample by Old and Oldest Elderly Cohorts

\begin{tabular}{|c|c|c|c|}
\hline Variable & Older Elderly n (\%) & Oldest Elderly n (\%) & P Value \\
\hline Sex & & & 0.003 \\
\hline Male & $356(44.9)$ & $97(35.1)$ & \\
\hline Female & $437(55.1)$ & $179(64.9)$ & \\
\hline \multicolumn{4}{|l|}{ Health Insurance } \\
\hline No & $742(95.0)$ & $256(96.6)$ & 0.184 \\
\hline Yes & $39(5.0)$ & $9(3.4)$ & \\
\hline Good Health Status & & & 0.385 \\
\hline No & $403(51.3)$ & $140(52.6)$ & \\
\hline Yes & $382(48.7)$ & $126(47.4)$ & \\
\hline Education & & & 0.170 \\
\hline Primary and below & $491(65.2)$ & $171(70.7)$ & \\
\hline Secondary & $241(32.0)$ & $68(28.1)$ & \\
\hline Tertiary & $21(2.8)$ & $3(1.2)$ & \\
\hline Area of residence & & & 0.121 \\
\hline Urban & $259(32.7)$ & $79(28.6)$ & \\
\hline Rural & $534(67.3)$ & $197(71.4)$ & \\
\hline House Tenure & & & 0.613 \\
\hline Rent free & $61(7.7)$ & $25(9.1)$ & \\
\hline Rented & $36(4.5)$ & $15(5.5)$ & \\
\hline Owned & $696(87.8)$ & $235(85.5)$ & \\
\hline
\end{tabular}

percent); self-reported good health was greater for urban (58.9 percent) than rural respondents (43.5 percent) (Table 2). Also retirement income was 2.4 times more for urban respondents than for rural respondents (5.7 percent).

Table 3 revealed that there was a statistical correlation between health insurance coverage and retirement income ( $p$ $=0.001)$. Respondents who reported receiving retirement income were 5.8 times more likely to have reported private health insurance coverage than the elderly who had not reported having received retirement income (Table 3 ).

Of the sample $(\mathrm{N}=1,069), 41.3$ percent answered the question of "Is your illness diagnosed as (chronic) recurring illness?" Of this number, 97.1 percent indicated a diagnosed (chronic) recurring ailment. A cross tabulation of diagnosed (chronic) recurring illness and age cohort of respondents showed no statistical correlation $(\mathrm{p}=0.509)$. Notwithstanding the aforementioned $\mathrm{p}$ value, 75.5 percent of those who responded to this question reported diabetes mellitus, hypertension and arthritis, with 37.3 percent having hypertension and 21.9 percent diabetes mellitus (Table 4). The number of respondents who indicated hypertension, diabetes and arthritis of the sample was 31.3 percent $(n=335)$; with 15.4 percent hypertension, 9.1 percent diabetes mellitus and 6.8 percent arthritis.

With respect to those who indicated being diagnosed (chronic) recurring ailment, 42.2 percent of women reported hypertension compared to 29.9 percent of men; 5.7 percent of men had asthma compared to 1.9 percent of women; 24.6 percent of women reported diabetes mellitus compared to 17.8 percent of men; and 21.3 percent of men reported arthritis compared to 13.4 percent of women (Table 5).

\section{Multivariate Analysis}

Predicting Good Health Status of Older and Oldest Elderly Jamaicans. Two factors were found to be statistically significant predictors of good health status of older and oldest elderly respondents. These were area of residence and sex of respondents. The model had a statistically significant predictive power (chi-square $=37.258, \mathrm{p}=0.001$; Hosmer and Lemeshow goodness of fit chi-square $=5.785, p=0.671)$. In addition, it was revealed that overall $58.39 \%$ of the data were correctly classified: $69.6 \%$ of those who indicated poor health status and $45.7 \%$ of those who indicated good health status (Table 6).

Based on Table 6, older and oldest elderly men reported a greater good health status than older and oldest elderly women $(\mathrm{OR}=1.410 ; 95 \% \mathrm{CI}$ : 1.048-1.897). Rural older and oldest elderly respondents indicated the lowest good health status $(\mathrm{OR}=1.00)$ compared to other residents (urban: $\mathrm{OR}=$ 1.670 ; $95 \% \mathrm{CI}: 1.071-2.606$; and other town dwellers: OR = $1.847 ; 95 \%$ CI: $1.327-2.572$ ). None of the other factors such as consumption, social support, crowding, health insurance coverage, cost of medical care, education, age of respondents, and the physical environment predicted good health status of older and oldest elderly respondents $(p>0.05)$. 
Table 2. Sociodemographic Characteristics of Sample by Urban-Rural Areas

\begin{tabular}{|c|c|c|c|}
\hline Variable & Urban n (\%) & Rural n (\%) & p Value \\
\hline Good Health Status & & & 0.001 \\
\hline No & $137(41.1)$ & $406(56.5)$ & \\
\hline Yes & $196(58.9)$ & $312(43.5)$ & \\
\hline Retirement Income & & & 0.001 \\
\hline No & $292(86.4)$ & $689(94.3)$ & \\
\hline Yes & $46(13.6)$ & $42(5.7)$ & \\
\hline Gender & & & 0.185 \\
\hline Male & $136(40.2)$ & $317(43.4)$ & \\
\hline Female & $202(59.8)$ & $414(56.6)$ & \\
\hline Marital status & & & 0.282 \\
\hline Married & $97(29.4)$ & $207(29.1)$ & \\
\hline Never married (include common law) & $80(24.2)$ & $175(24.6)$ & \\
\hline Divorced & $10(3.0)$ & $8(1.1)$ & \\
\hline Separated & $6(1.8)$ & $18(2.3)$ & \\
\hline Widowed & $135(41.5)$ & $305(42.9)$ & \\
\hline Age group & & & 0.214 \\
\hline Older Elderly & $259(76.6)$ & $534(73.1)$ & \\
\hline Oldest Elderly & $79(23.4)$ & $197(26.9)$ & \\
\hline Utilization of Health Facilities & & & 0.293 \\
\hline Private & $39(55.7)$ & $119(51.1)$ & \\
\hline Public & $31(44.3)$ & $114(48.9)$ & \\
\hline Private Health Insurance coverage & & & 0.001 \\
\hline No & $296(89.7)$ & $702(98.0)$ & \\
\hline Yes & $34(10.3)$ & $14(2.0)$ & \\
\hline Education & & & 0.001 \\
\hline Primary and below & $196(61.4)$ & $466(68.9)$ & \\
\hline Secondary & $105(32.9)$ & $204(30.2)$ & \\
\hline Tertiary & $18(5.6)$ & $6(0.9)$ & \\
\hline Social class & & & 0.001 \\
\hline Poorest & $42(12.4)$ & $197(26.9)$ & \\
\hline Poor & $45(13.3)$ & $171(23.4)$ & \\
\hline Low Middle & $59(17.5)$ & $136(18.6)$ & \\
\hline Upper Middle & $77(22.8)$ & $117(16.0)$ & \\
\hline Wealthiest & $115(34.0)$ & $110(15.0)$ & \\
\hline Per capita consumption* Mean (SD) & US\$1,820.23 (\$1,399.19) & US\$1,263.21 (\$1,187.49) & 0.001 \\
\hline Crowding Mean (SD) & $1.05(0.85)$ & $1.15(0.83)$ & 0.071 \\
\hline Crime Index Mean (SD) & $1.61(7.53)$ & $0.74(3.02)$ & 0.007 \\
\hline Living Alone & $75(22.2)$ & $146(20.0)$ & 0.405 \\
\hline
\end{tabular}


Table 3. Health Insurance by Retirement Income

\begin{tabular}{|c|c|c|c|}
\hline \multirow{2}{*}{} & \multicolumn{3}{|c|}{ Retirement Income } \\
\cline { 2 - 4 } & No & Yes & Total \\
\hline \hline Health Insurance Coverage \\
\hline No & 96.7 & 81.0 & 100.0 \\
\hline Yes & 3.3 & 19.0 & 4.6 \\
\hline Total & $\mathbf{9 6 2}$ & $\mathbf{8 4}$ & $\mathbf{1 , 0 4 6}$ \\
\hline$\chi^{2}(1)=4.610, p$ value $=0.001$. & & & \\
\hline
\end{tabular}

Table 4. Chronic (Recurring) Illness by Age Cohort

\begin{tabular}{|c|c|c|c|}
\hline \multirow{2}{*}{} & \multicolumn{3}{|c|}{ Age Cohort } \\
\cline { 2 - 4 } \multicolumn{2}{|c|}{ Older Elderly } & Oldest Elderly & Total \\
\hline \hline \multirow{2}{*}{ Chronic Illness } & 3.9 & 2.8 & 3.6 \\
\hline Cold & 1.2 & 2.8 & 1.6 \\
\hline Diarrhoea & 3.9 & 1.9 & 3.4 \\
\hline Asthma & 23.4 & 17.6 & 21.9 \\
\hline Hypertension & 37.1 & 38.0 & 37.3 \\
\hline Diabetes & 16.5 & 16.7 & 16.5 \\
\hline Arthritis & 11.7 & 15.7 & 12.7 \\
\hline Other & 2.4 & 4.6 & 2.9 \\
\hline No & $\mathbf{3 3 4}$ & $\mathbf{1 0 8}$ & $\mathbf{4 4 2}$ \\
\hline \multicolumn{2}{|c|}{ Total } & &
\end{tabular}

Table 5. Chronic (Recurring) Illness by Gender

\begin{tabular}{|l|c|c|c|}
\hline \multicolumn{2}{|c|}{} & \multicolumn{3}{c|}{ Gender } \\
\cline { 2 - 4 } & Male & Female & Total \\
\hline \hline Chronic Illness & 4.6 & 3.0 & 3.6 \\
\hline Cold & 1.7 & 1.5 & 1.6 \\
\hline Diarrhoea & 5.7 & 1.9 & 3.4 \\
\hline Asthma & 17.8 & 24.6 & 21.9 \\
\hline Hypertension & 29.9 & 42.2 & 37.3 \\
\hline Diabetes & 21.3 & 13.4 & 16.5 \\
\hline Arthritis & 16.7 & 10.1 & 12.7 \\
\hline Other & 2.3 & 3.4 & 2.9 \\
\hline No & $\mathbf{1 7 4}$ & $\mathbf{2 6 8}$ & $\mathbf{4 4 2}$ \\
\hline \multicolumn{2}{|l|}{ Total } & &
\end{tabular}

\section{DISCUSSION}

The current study has shown that the health status of older and oldest elderly in Jamaica is relatively moderate, as 48 out of every 100 older and oldest elderly reported good health status. It was found that there was no statistical difference between the self-reported good health status of older people (ages $75-84$ years) and oldest elderly (ages 85 years

Table 6. Logistic Regression on Good Health of Old and Oldest Elderly Jamaicans and Some Explanatory Variables, $\mathbf{N}=958$

\begin{tabular}{|c|c|c|c|c|c|c|c|}
\hline \multirow{2}{*}{ Variables } & \multirow{2}{*}{ Coefficient } & \multirow{2}{*}{ Std Error } & \multirow{2}{*}{ Wald Statistics } & \multirow{2}{*}{ p Value } & \multirow{2}{*}{ Odds Ratio } & \multicolumn{2}{|c|}{$95.0 \%$ C.I. } \\
\hline & & & & & & Lower & Upper \\
\hline "Average Consumption & 0.000 & 0.000 & 0.334 & 0.563 & 1.000 & 1.000 & 1.000 \\
\hline Environment & 0.103 & 0.143 & 0.517 & 0.472 & 1.108 & 0.837 & 1.468 \\
\hline Other Towns & 0.614 & 0.169 & 13.213 & 0.000 & 1.847 & 1.327 & 2.572 \\
\hline Urban & 0.513 & 0.227 & 5.115 & 0.024 & 1.670 & 1.071 & 2.606 \\
\hline \multicolumn{5}{|l|}{$\dagger$ Rural area } & \multicolumn{3}{|l|}{1.000} \\
\hline Social support & -0.165 & 0.134 & 1.513 & 0.219 & 0.848 & 0.652 & 1.103 \\
\hline Sex & 0.343 & 0.151 & 5.145 & 0.023 & 1.410 & 1.048 & 1.897 \\
\hline Number of male & 0.008 & 0.074 & 0.012 & 0.914 & 1.008 & 0.872 & 1.165 \\
\hline Number of female & 0.084 & 0.076 & 1.227 & 0.268 & 1.088 & 0.937 & 1.262 \\
\hline Number of children & 0.050 & 0.062 & 0.644 & 0.422 & 1.051 & 0.930 & 1.188 \\
\hline Age & -0.019 & 0.012 & 2.501 & 0.114 & 0.981 & 0.957 & 1.005 \\
\hline Middle Quintile & 0.023 & 0.188 & 0.015 & 0.901 & 1.024 & 0.709 & 1.478 \\
\hline Wealthiest Quintiles & 0.088 & 0.205 & 0.185 & 0.668 & 1.092 & 0.731 & 1.631 \\
\hline \multicolumn{5}{|l|}{$\dagger$ Poorest-poor quintiles } & \multicolumn{3}{|l|}{1.000} \\
\hline Health Insurance & 0.241 & 0.326 & 0.549 & 0.459 & 1.273 & 0.672 & 2.411 \\
\hline Cost of medical care & 0.000 & 0.000 & 0.203 & 0.652 & 1.000 & 1.000 & 1.000 \\
\hline Primary Education & 0.180 & 0.142 & 1.592 & 0.207 & 1.197 & 0.905 & 1.582 \\
\hline Constant & 0.774 & 1.024 & 0.572 & 0.450 & 2.168 & & \\
\hline
\end{tabular}

Overall correct classification $=58.3 \%$.

Correct classification of cases of poor health status $=69.6 \%$.

Correct classification of cases of good health status $=45.7 \%$.

$\uparrow$ Reference group. 
and older). Nine of every 100 older-to-oldest elderly had diabetes mellitus; 15 out of every 100 hypertension and 7 out of every 100 had arthritis. In addition, there was a statistical correlation between good health status and area of residence, or self-reported (chronic) recurring illness and age cohort. Furthermore, the data showed that older and oldest elderly Jamaicans who dwelled in rural area had the lowest selfreported good health compared to those who resided in other towns and urban areas. Continuing, those who resided in other towns reported the greatest good health status. Approximately, twice more women reported being diagnosed with (chronic) recurring illness compared to men.

Eldemire [32] opined that ageing population is associated with increased disability, and if this is so then there should be more illness with ageing. The current study does not concur with Eldemire findings, that as people age (older to oldest elderly) they would report more disabilities. This approach emphasizes the longevity of the cells, in relation to the number of years the organism can live. Thus, in this construction the human body (an organism) is valued based on physical appearance and/or state of the cells. Embedded in this apparatus is the genetic composition of the survivor.

Gompertz's law in Gavriolov and Gavrilova [7] demonstrates the fundamental quantitative theory of ageing and mortality of certain species (the examples here are as follows - humans, human lice, rats, mice, fruit flies, and flour beetles). Gompertz's law went further to establish that human mortality increases twofold with every 8 years of an adult life, which means that ageing increases in geometric progression. This phenomenon means that human mortality increases with the age of the human adult, but that this becomes less progressive in advanced ageing. Thus, biological ageing is a process where the human cells degenerate with years (i.e. the cells die with increasing age), which is explored in evolutionary biology [33, 34]. But studies have shown that using the evolutionary theory for "late-life mortality plateaus" failed because of the unrealistic set of assumptions on which the theory is based [35-38].

The reliability theory, on the other hand, is a better fitted explanation for the ageing of humans than that argued by Gompertz's law, as the 'failing law' speaks to the deterioration of human organisms with age [7] as well as the nonageing term. The latter, based on Gavrilov and Gavrilova [7], can occur because of accidents and acute infection, which are called "extrinsic causes of death. While Gompertz's law speaks to mortality in the ageing organism due to age-related degenerative illnesses such as heart diseases and cancers, a part of the reliability function is Gompertz's function as well as the non-ageing component. The current study did not find a statistical difference between self-reported diagnosed (chronic) recurring illness and older and oldest elderly elderly; this can be as a result of the data. Despite the fact that people are the best judge of what affects them, there is a clear disparity here between biological ageing theorists' findings and the self-reported results of older and oldest elderly Jamaicans.

The World Health Organization $[39,40]$ put forward a position that there is a disparity between contracting many diseases and the gender constitution of an individual. One health psychologist, Rice [41], in concurring with WHO, argued that differences in death and illnesses are the result of differential risks acquired from functions, stress, life styles and 'preventative health practices'.

Rice believed that this health difference between the sexes is due to social support. Other scholars explained that it is owing to epidemiological trends [42] i.e. lifestyle practices justify the advantages that women enjoy compared to men concerning health status. The current study found that older and oldest elderly men had superior good health status to that of women, with men being 1.4 times more likely to report good health than women. A survey done by Rudkin found that women have lower levels of economic wellbeing than men [43], and this is one of the justifications for the latter group reporting superior good health status. This finding is further sanctioned by Havenman et al. [44] whose study revealed that retired men's wellbeing was higher than that of their female counterparts, because men usually received more material resources, and more retirement benefits compared to women ages 65 years and older. Thus, with men receiving more than women and having more durable possessions than women, their general satisfaction with life (including health) will be better than their women counterparts. There is a paradox here, as Bourne showed from statistics [3, $10]$ that the life expectancy of women in Jamaica has been at least 3 years $(1880-1882)$ to 6 years $(2002-2004)$ longer, yet they have a lower good health status.

A part of the gender health disparity that was put forward is owing to the culture. Among the gender roles ascribed to Caribbean males are the protection of the family, children, wife or girlfriend, and parents. The man is expected to handle the laborious tasks such as lifting heavy items, pruning trees and hedges and taking out the garbage, while maintaining a special protective role for his parents, in particular his mother. A Caribbean male finds it impossible to tolerate someone criticizing his mother or belittling her, without becoming abusive or even confrontational. It is not that Caribbean males take a minimalistic role in regard to the family, but it is primarily the gender specification of these societies along with task specialization. Another cultural bias that emerged from the laborious tasks they are expected to undertake is illness. Illness is an indicator of weakness and lowered masculinity, which explains men's unwillingness to seek preventative care, visit health facilities and report illness. This then accounts for the lowered good health status of women and the greater one reported by men. Despite this reality, let us examine particular health conditions.

Women have a higher propensity than men to contract particular conditions such as depression, osteoporosis and osteoarthritis [39, 45]. Herzog [45] noted that “... it appears that older women are more likely to be impaired by their health problems, while older men are more likely to die from them." A study by Schoen et al. [46] found that a group of adolescents revealed something different from that which was reported by WHO. The researchers found that males are more likely than females to feel stressed; 'overwhelmed' or 'depressed', and they attributed this to men's limited social networks. Other researchers have agreed with Schoen et al. that men in general tend to be more stressed and less healthy than females, and further argued that men can use denial, distraction, alcoholism and other social strategies to conceal their illness or disabilities [47-50]. On the other hand, Herzog [45] in Physical and Mental Health in Older Women, 
using studies from a number of experts, wrote that females had higher rates of depression than their male counterparts.

Data for the Caribbean showed that hypertension and arthritis are morbidities that significantly plague both men and women [26]. The current study revealed that diabetes mellitus was the leading cause of illness among older and oldest elderly in Jamaica, followed by hypertension and arthritis, which differs from a past study [17] that had hypertension as the leading cause of morbidity of the elderly (43.4 percent), followed by arthritis (39.8 percent) and diabetes mellitus (10.2 percent). When reported illness was cross tabulated by sex of older and oldest elderly respondents, the findings showed that 1.4 percent more women had diabetes mellitus than men and this was the same for hypertensive older and oldest elderly Jamaicans. On the other hand, there were 1.6 times more old and oldest elderly Jamaican men with self-reported arthritis than women. These chronic noncommunicable diseases continue to interface within the functional lives of the elderly, which means that they are indeed living longer but are faced with lower levels of good health than young adults (ages 15 to 29 years) and middle-aged adults (ages 30 to 59 years). However, there was no statistical difference between self-reported ill and older and oldest elderly age cohorts in this study, suggesting that health disparity is not between older elderly and oldest elderly Jamaicans, but rather between older and oldest elderly and other age cohorts, such as young adults and middle-aged adults. Bourne's study [10] of 3,009 elderly Jamaicans (ages 60 years and older) found a low general wellbeing of respondents (3.9 out of $14 \pm 2.3$ ) which concurs with the current study. This study has refined the aforementioned one, by showing that there is no statistical difference between the self-reported health status of older and oldest elderly Jamaicans; but it did not examine the young old (ages 60 to 74 years) and so it is unable to state whether there was a difference between young old and old and oldest elderly respondents.

The old and oldest elderly are less likely to be productively employed in the labour force than middle-aged adults. This does not mean that they cannot be actively engaged in many other activities. Old and oldest elderly Jamaicans are involved in social work, home gardening, and actively engaged in extended family functions such as the rearing of grand-children. In this study 36 out of every 100 old and oldest elderly reported that their grandchildren lived with them. In Jamaica, the extended family is still cohesive [20] and the current study showed that this has not changed, as approximately 54 out of every 100 persons were either married or in common-law unions; but 8 out of every 10 old and oldest elderly were not living alone, suggesting that the extended family is still alive in 2002.

In 1997, Statistics from the Planning Institute of Jamaica and the Statistical Institute of Jamaica [51] revealed that 54.3 percent of elderly (ages 60 years and over) lived in rural areas, and the current study showed that approximately 7 out of every 10 old and oldest elderly lived in rural areas, compared to 6 out of 10 for those 60 years and older of the population. In addition, 20 out of every 100 Jamaicans were below the poverty line, compared to 25 out of every 100 in rural Jamaica. Given that the elderly substantially lived in rural areas and that poverty for this group was 10.2 percent (in 2007), it is not surprising that the old and oldest elderly in this area of residence had a lower level of good health status than the urban old and oldest elderly in Jamaica. It should be noted here that studies have shown that income was related to good health $[52,53]$, but this is not the case for the current study (old and oldest elderly Jamaicans).

Poverty leads to ill-health, suggesting that the poor are less likely to have superior 'good health status' to those in middle to upper classes [54]. Murray [54] opined that the interrelation between poverty and health is expressed in poor nutrition, improper sanitation and water quality and inadequate housing, and these contribute to a lower health status. Other studies [55-57] have refined this relationship by showing that persistent poverty affects health and even mortality, as well as accounting for much of the malnutrition in developing countries [58]. Poverty and poor health is not only outside of the Caribbean as a study conducted in Jamaica [59] revealed that the least health was reported by those in the lower class. This is not the case for the old and oldest elderly Jamaicans, as there was no statistical difference between the various social standings (i.e. lower, middle and upper classes) and good health status. The rationale for this is embedded in the definition of health, which means that health is tied to the living by more than difficulties of hypertension, diabetes mellitus and arthritis. Those conditions are not viewed as poor health, as they are permanent conditions, and therefore may not be construed as such.

In studies done on elderly Jamaicans (ages 60+ years), physical environment, age, the number of males, females and children in a household, education, consumption, health insurance and cost of medical care were significantly related to good health $[3,4,10]$, as is also the case in Barbados [30], Canada [60] and the United States [61]. However, those variables are not related to good health for the old and oldest elderly population in Jamaica, suggesting that variables are not what account for good health in old and oldest elderly respondents. In Bourne studies on elderly Jamaicans generally $[3,4,10]$, it was revealed that crowding, marital status, area of residence, physical environment and gender accounted for the majority of the explanatory power of good health, and that only crowding and marital status were not included in the current study, indicating that good health for ages 75 years and older was not due to identified variables or those affecting $60+$ years and older. Embedded in this figure is that most of the variables that were predictors of good health of elderly were more explanations of young elderly (60 to 74 years) than the older and oldest elderly elderly.

The validity of using people's assessment of their life satisfaction and health is old and has already been resolved. Nevertheless, it will be succinctly put forward here for those who are not cognizant of this discourse. Scholars have established that there is a statistical association between subjective wellbeing (self-reported wellbeing) and objective wellbeing [62-68], and Diener went further when he found a strong correlation between the two variables [68]. Gaspart [63] opined on the difficulty of objective quality of life (GDP per capita) and the need to use self-reported wellbeing in assessing the wellbeing of people. He wrote, "So its objectivism is already contaminated by post-welfarism, opening the door to a mixed approach, in which preferences matter as well as objective wellbeing" [63], which speaks to the neces- 
sity of using a measure that approximates more to this multidimensional construct, rather than continuing with the traditional income per capita approach. Another group of scholars emphasized the importance of measuring wellbeing outside of welfarism and/or pure objectification, when they said that "Although GDP per capita is usually used as a proxy for the quality of life in different countries, material gain is obviously only one of many aspects of life that enhance economic wellbeing" [69] and that wellbeing depends on both the quality and the quantity of life lived by the individual [70]. Another study found that self-rated health was a strong predictor of mortality, and remained the same even when controlled for physical health [64]. As such, self-rated health encompasses a more extensive coverage of health (such as physical status; cognitive, emotional and social health) that are in keeping with old age than the objective health, which are subtle and difficult to measure objectively using physical health assessment.

\section{CONCLUSIONS}

In summary, we now have a better understanding of those factors that account for older and oldest elderly good health. While the data were well fitted for the model, the explanatory power was low for those identified predictive factors. This means that the good health of this age cohort is not influenced by income, social standing and many other factors that predict health status for the general populace, and that there is a need to examine lifestyle risk factors, culture and the meaning system of this group, as those variables may provide more answers to the good health of Jamaicans 75 years and older. This quantitative assessment has provided us with pertinent answers, but it is clear from the findings that more information is needed on this age cohort and that this can be had by qualitative methodology. The researcher recommends the use of qualitative methodologies to provide in-depth understanding of the culture and meaning system of this cohort as they can provide valuable insight into some of the determinants of good health.

\section{ACKNOWLEDGEMENTS}

The author would like to thank the Data Bank in the Sir Arthur Lewis Institute of Social and Economic Studies, the University of the West Indies, Mona, Jamaica for making the dataset (Jamaica Survey of Living Conditions, 2002) available. It was used for the current study.

\section{REFERENCES}

[1] United Nations. World Population Ageing 1950-2050. New York: United Nations 2002.

[2] Eldemire-Shearer D. Ageing- A new challenge to health care in the new millennium. West Ind Med J 2001; 50: 95-9.

[3] Bourne PA. Growing Old in Jamaica: Population Ageing and Senior Citizens' Wellbeing. Kingston: Community Health and Psychiatry, Faculty of Medical Sciences, The University of the West Indies, Mona: Jamaica 2009.

[4] Bourne PA. Determinants of well-being of the Jamaican Elderly. Unpublished Thesis, Department of Sociology, Psychology and Social Work, the University of the West Indies, Mona: Kingston 2007.

[5] Castellón RH. Population Ageing in Cuba. Malta: International Institute on Ageing. United Nations 1994.

[6] Gavrilov LA, Heuveline P. In: Demeny P, McNicol G, Eds. Aging of Population. Quoted in the Encyclopedia of Population. New York: Macmillan 2003.

[7] Gavrilov LA, Gavrilova NS. The reliability theory of aging and longevity. J Theor Biol 2001; 213: 527-45.
[8] Gavrilov LA, Gavrilova NS. The biology of life Span: A Quantitative Approach. New York: Harwood Academic Publisher 1991.

[9] WHO. WHO Issues New Healthy Life Expectancy Rankings: Japan Number One in New 'Healthy Life' System? Washington D.C. \& Geneva: WHO 2000.

[10] Bourne PA. Medical Sociology: Modelling Well-being for elderly People in Jamaica. West Ind Med J 2008; 57: 596-604.

[11] WHO. Older Persons in Emergencies: An Active Ageing Perspective. Geneva: WHO 2008.

[12] Bourne PA. Health Determinants: Using secondary data to model predictors of wellbeing of Jamaicans. West Ind Med J 2008; 57 : 476-81.

[13] Eldemire D. The Jamaican elderly: A socioeconomic perspective and policy implications. Soci Econ Stud 1997; 46: 175-93.

[14] Eldemire D. Older women: a situational analysis, Jamaica 1996. New York: United Nations Division for the Advancement of Women 1996.

[15] Eldemire D. A situational analysis of the Jamaican elderly, 1992. Kingston: Planning Institute of Jamaica 1995.

[16] Eldemire D. The elderly in Jamaica: A gender and development perspective. In: Robert JH, Kitts J, Arsenault LJ, Eds. Gender, health, and sustainable development. Perspective from Asia and the Caribbean. Proceedings of workshops held in Singapore, 23-26 January 1995 and in Bridgetown, Barbados, 6-9 December 1994. Ottawa: International Development Research Centre 1995.

[17] Eldemire D. The elderly and the family: the Jamaican experience. Bull East Caribbean Aff 1994; 19: 31-46.

[18] Eldemire D. The elderly - A Jamaican perspective. G Gerald AC (Ed.). The elderly in the Caribbean: Proceedings of continuing medical education symposium. Kingston, Jamaica: University Printery 1987.

[19] Eldemire D. The clinical's approach to the elderly patient. G Grell AC, Ed. The elderly in the Caribbean: Proceedings of continuing medical education symposium. Kingston, Jamaica: University Printery 1987.

[20] Eldemire D. Health care in Jamaica. World Health Forum 1995; 16: 344-7.

[21] Morrison E. Diabetes and hypertension: twin trouble. Cajanus 2000; 33: 61-3.

[22] Barrett V. Analysis of the Jamaica government's policy (1981 1986) on institutional and community programmes for the elderly. Kingston: B.Sc. Public Administration. Mona: University of the West Indies 1987.

[23] Eldemire-Shearer D, Paul TJ, Morris C. Ageing males - an emerging area of concern. West Ind Med J 2002; 51: 139-42.

[24] Anthony BJ. Nutritional assessment of the elderly. Cajanus 1999; 32: 201-16.

[25] Blue Cross of Jamaica. The Jamaican handbook for the elderly. Kingston, Jamaica: L.M.H. Publishing 2001.

[26] Caribbean Food and Nutrition Institute. Health of the elderly. Cajanus 1999; 32: 217-40.

[27] Morgan O, Ed. Health Issues in the Caribbean. Kingston: Ian Randle 2005.

[28] Homer D, Lemeshow S. Applied logistic regression, $2^{\text {nd }}$ ed. New York John: Wiley \& Sons Inc. 2000.

[29] Cohen L, Holliday M. Statistics for Social Sciences. London, England: Harper \& Row 1982.

[30] Hambleton IR, Clarke K, Broome HL, et al. Historical and current predictors of self-reported health status among elderly persons in Barbados. Rev Panam Salud Pública 2005; 17: 342-52.

[31] Grossman M. The demand for health - a theoretical and empirical investigation. New York: National Bureau of Economic Research 1972.

[32] Eldemire-Shearer D. Ageing- a new challenge to health care in the new millennium. West Ind Med J 2001; 50: 95-9.

[33] Medawar PB. Old age and natural death. Medawar PB, Ed. Mod. Q. 2:30-49. [Reprinted in the Uniqueness of the Individual New York: Basic Books 1946; pp. 17-43.

[34] Charlesworth B. Evolution in Age-structured Populations, 2nd Ed. Cambridge: Cambridge University Press 1994.

[35] Mueller L, Rose MR. Evolutionary theory predicts late-life mortality plateaus. Proc Natl Acad Sci USA 1996; 93: 15249-53.

[36] Charlesworth B, Partridge L. Ageing: leveling of the grim reaper. Curr Biol 1997; 7: R440-R442. 
[37] Pletcher SD, Curtsinger JW. Mortality plateaus and the evolution of senescence: why are old-age mortality rates so low? Evolution 1998; 52: 454-64

[38] Wachter KW. Evolutionary demographic models for mortality plateaus. Proc Natl Acad Sci USA 1999; 96: 10544-7.

[39] WHO. Ageing and Health, Epidemiology. WHO, Regional Office in Africa; 2005. Available from: http://www.afro.who.int/ageing andhealth/epidemiology.html [Accessed March 30, 2009].

[40] WHO. Healthy Ageing: Practical pointers on keeping well. Regional Office for the Western Pacific, Manila, Philippines: WHO; 2005. Available from: http://wpro.who.int [Accessed March 30, 2009].

[41] Rice PL. Health psychology. CA, USA: Brooks/Cole Publishing 1998.

[42] Rodin J, Ickovic JR. Women's health: review and research agenda as we approach the 21 st century. Am Psycholog 1990; 45: 1018-34.

[43] Rudkin L. Gender differences in economic well-being among the elderly of Java. Demography 1993; 30: 209-26.

[44] Havenman R, Holden K, Wilson K, Wolfe B. Social security, age of retirement, and economic well-being: inter-temporal and demographic patterns among retired-worker beneficiaries. Demography 2003; 40: 369-94.

[45] Herzog AR. Physical and Mental Health in Older Women: Selected Research Issues and Data Sources. In: Hendricks JA, Ed. Health and Economic Status of Older Women: Research Issues and Data Sources. New York, USA: Baywood 1989.

[46] Schoen C, Davis K, DesRoches C, Shekhdar A. The health of adolescent boys: commonwealth Fund survey findings. New York: Commonwealth Fund 1998.

[47] Friedman HS, Ed. Hostility, coping, and health. Washington, DC: Am Psychological Association 1991.

[48] Kopp MS, Skrabski A, Szedmak S. Why do women suffer more and live longer? Psychosom Med 1998; 60: 92-135.

[49] Weidner G, Collins RL. Gender, coping, and health. In: Krohne HW, Ed. Attention and avoidance. Seattle, WA: Hogrefe \& Huber 1993; pp. 241-65.

[50] Sutkin L, Good G. Therapy with men in health-care settings. In: Scher M, Stevens M, Good G, Eichenfield GA, Eds. Handbook of counseling and psychotherapy with men. Thousand Oaks, CA: Sage Publications 1987; pp. 372-87.

[51] Planning Institute of Jamaica (PIOJ). Statistical Institute of Jamaica (STATIN). Jamaica Survey of Living Conditions, 2007. Kingston: PIOJ \& STATIN 2008.

[52] Marmot M. The influence of Income on Health: Views of an Epidemiologist: Does money really matter? Or is it a maker for something else? Health Aff 2003; 21: 31-46.
[53] Stronks K, Van De Mheen, Van Den Bos J, MacKenbach JP. The Interrelationship between Income, health and employment status. Int J Epidemiol 1997; 26: 592-600.

[54] Murray S. Poverty and health. Can Med Assoc J 2006; 174: 923.

[55] Lynch JW, Kaplan GA, Shema SJ. Cumulative impact of sustained economic hardship on physical cognitive, psychological, and social functioning. N Engl J Med 1997; 337: 1889-95.

[56] Menchik PL. Economic status as a determinant of mortality among black and white older men: does poverty kill? Popul Stud 1993; 47: 427-36.

[57] Zick CD, Ken RS. Marital transitions, poverty and gender differences in mortality. J Marriage Fam 1991; 53: 327-36.

[58] Muller O, Krawinkel M. Malnutrition and health in developing countries. Can Med Assoc J 2005; 173: 279-86.

[59] Powell LA, Bourne P, Waller L. Probing Jamaica's Political culture: Main Trends in the July-August 2006, Leadership and Governance Survey. Kingston: Centre for Leadership and Governance, Department of Government, University of the West Indies, Jamaica: Mona 2007; vol. 1.

[60] Moore EG, Rosenberg MW, McGuinness D. Growing old in Canada: demographic and geographic perspectives. Ontario: Nelson 1997.

[61] Smith JP, Kington R. Demographic and economic correlates of health in old age. Demography 1997; 34: 159-70.

[62] Diener E. Subjective well-being: the science of happiness and a proposal for a national index. Am Psychol 2000; 55: 34-43.

[63] Gaspart F. Objective measures of well-being and the cooperation production problem. Soc Choice Welfare 1998; 15: 95-112.

[64] Idler EL, Benyami Y. Self-rated health and mortality: a review of twenty-seven community studies. J Health Soc Behav 1997; 38: 21 37.

[65] Jylha M, Guralnik JM, Ferrucci L, Jokela J, Heikkinen E. Is selfrated health comparable across cultures and genders. J Gerontol 1998; 53B: S144-S145.

[66] Larson R. Thirty years of research on the subjective well-being of older Americans. J Gerontol 1978; 33: 109-25.

[67] Zimmer A, Natividad JN, Lin Hui-Sheng, Chayovan N. A crossnational examination of the determinants of self-assessed health. J Health Soc Behav 2000; 41: 465-81.

[68] Diener E. Subjective well-being. Psychol Bull 1984; 95: 542-75.

[69] Becker GS, Philipson TJ, Soares RR. The quantity and quality of life and the evolution of world inequality; 2004. Available from: http://www.spc.uchicago.edu/prc/pdfs/becker05.pdf\#search=\% $\% 2 \mathrm{pr}$ eston $\% 2 \mathrm{C} \% 20$ quality $\% 20$ of $\% 201$ ife $\% 22$ [Accessed August 22, 2006].

[70] Easterlin RA. Income and happiness: towards a unified theory. Econ J 2001; 111; 473: 465-84.

(C) Paul A. Bourne; Licensee Bentham Open.

This is an open access article licensed under the terms of the Creative Commons Attribution Non-Commercial License (http: //creativecommons.org/licenses/bync/3.0/) which permits unrestricted, non-commercial use, distribution and reproduction in any medium, provided the work is properly cited. 